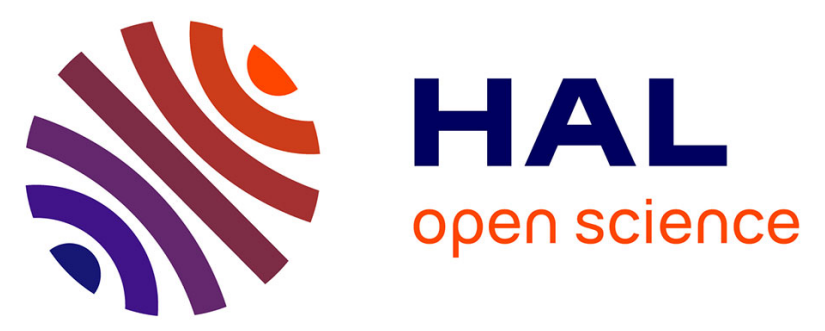

\title{
A Fluorine-Free Precise Polymer Electrolyte for Efficient Proton Transport: Experiments and Simulations
} Benjamin A Paren, Bryce A Thurston, Arjun Kanthawar, William J Neary, Aaron Kendrick, Manuel Maréchal, Justin G Kennemur, Mark J Stevens, Amalie L Frischknecht, Karen I Winey

\section{To cite this version:}

Benjamin A Paren, Bryce A Thurston, Arjun Kanthawar, William J Neary, Aaron Kendrick, et al.. A Fluorine-Free Precise Polymer Electrolyte for Efficient Proton Transport: Experiments and Simulations. Chemistry of Materials, 2021, 33 (15), pp.6041-6051. 10.1021/acs.chemmater.1c01443 . hal-03423095

\section{HAL Id: hal-03423095 \\ https://hal.science/hal-03423095}

Submitted on 9 Nov 2021

HAL is a multi-disciplinary open access archive for the deposit and dissemination of scientific research documents, whether they are published or not. The documents may come from teaching and research institutions in France or abroad, or from public or private research centers.
L'archive ouverte pluridisciplinaire HAL, est destinée au dépôt et à la diffusion de documents scientifiques de niveau recherche, publiés ou non, émanant des établissements d'enseignement et de recherche français ou étrangers, des laboratoires publics ou privés. 
TITLE: A Fluorine-free Precise Polymer Electrolyte for Efficient Proton Transport: Experiments and Simulations

\section{AUTHORS}

Benjamin A. Paren ${ }^{1}$, Bryce A. Thurston ${ }^{2}$, Arjun Kanthawar ${ }^{1}$, William J. Neary ${ }^{3}$, Aaron

Kendrick ${ }^{3}$, Manuel Maréchal ${ }^{4}$, Justin G. Kennemur ${ }^{3}$, Mark J. Stevens ${ }^{2 *}$, Amalie L.

Frischknecht ${ }^{2 *}$, Karen I. Winey ${ }^{l^{*}}$

*corresponding authors K.I.W. (winey@ seas.upenn.edu), A.L.F. (alfrisc@ sandia.gov), and

M.J.S. (msteve@sandia.gov)

\section{AUTHOR AFFILIATIONS/ADDRESSES}

${ }^{1}$ University of Pennsylvania, Dept. Of Materials Science \& Engineering, 3231 Walnut St,

Philadelphia, PA, 19104

${ }^{2}$ Center for Integrated Nanotechnologies, Sandia National Laboratories, P.O. Box 5800 MS

1495, Albuquerque, NM, 87185-1411

${ }^{3}$ Florida State University, Dept. Of Chemistry and Biochemistry, 95 Chieftan Way, DLC 118,

Tallahassee, FL 32306, USA

${ }^{4}$ Univ. Grenoble Alpes, CNRS, CEA, IRIG-SyMMES, 38000 Grenoble, France 


\begin{abstract}
Designing polymers with controlled nanoscale morphologies and scalable synthesis is of great interest in the development of fluorine-free materials for proton exchange membranes in fuel cells. This study focuses on a precision polyethylene with phenylsulfonic acid branches at every $5^{\text {th }}$ carbon, p5PhSA, with a high ion-exchange capacity $(4.2 \mathrm{mmol} / \mathrm{g})$. The polymers selfassemble into hydrophilic and hydrophobic co-continuous nanoscale domains. In the hydrated state, the hydrophilic domain, comprised of the polar sulfonic acid moieties and water, serves as a pathway for efficient mesoscopic proton conductivity. The morphology and proton transport of p5PhSA are evaluated under hydrated conditions using in situ X-ray scattering and electrochemical impedance spectroscopy techniques. At $40{ }^{\circ} \mathrm{C}$ and $95 \%$ relative humidity, the proton conductivity of $\mathrm{p} 5 \mathrm{PhSA}$ is $0.28 \mathrm{~S} / \mathrm{cm}$, which is four times greater than Nafion ${ }^{\mathrm{TM}} 117$ under the same conditions. Atomistic molecular dynamics (MD) simulations are also used to elucidate the interplay between the structure and the water dynamics. The MD simulations show strong nanophase separation between the percolated hydrophilic and hydrophobic domains over a wide range of water contents. The percolated hydrophilic nanoscale domain facilitates the rapid proton transport in $\mathrm{p} 5 \mathrm{PhSA}$ and demonstrates the potential of precise hydrocarbon-based polymers as processible and effective proton exchange membranes.
\end{abstract}




\section{INTRODUCTION}

Perfluorosulfonic acid (PFSA) polymers have been used for decades as proton exchange membranes (PEMs), because they have excellent phase separation and proton transport properties, concomitantly with high chemical stability which allows them to be used in efficient membrane-electrode assemblies. ${ }^{1,2}$ Under high humidity or hydrated conditions, some of the best-performing PEMs exhibit proton conductivities as high as $0.1-0.2 \mathrm{~S} / \mathrm{cm}$ while still maintaining mechanical stability, which is critical for their application in their fuel cell. ${ }^{1,3}$ The high conductivity often is driven by strong nanophase separation between hydrophobic and swollen hydrophilic domains, in combination with sufficient charge concentration, or ionexchange capacity (IEC). In PEMs, the primary mechanisms of proton transport are vehicular motion (pure diffusion of $\mathrm{H}_{3} \mathrm{O}^{+}$ions in $\mathrm{H}_{2} \mathrm{O}$ ) and the Grotthuss mechanism, which dominates at high water content. ${ }^{1,3-6}$

However, PFSA membranes contain fluorine which adds expense and can lead to HF formation during degradation, and they have reduced performance at higher temperatures. ${ }^{1,5,7}$ These issues have led to interest in hydrocarbon-based PEMs, which typically have phenyl groups in the backbone for increased thermal stability and mechanical rigidity. They often have scalable chemistries, and do not contain fluorine, which may lead to lower cost and polymerizations under milder conditions. A significant disadvantage of current hydrocarbonbased PEMs is their reportedly weaker nanophase separation relative to PFSAs, as identified using X-ray scattering, and this weaker nanophase separation leads to slower proton transport. ${ }^{3,4,89}$ Efforts to optimize the properties of hydrocarbon-based PEMs have included blending, forming nanocomposites, and using alternative chemistries. ${ }^{3}$ Our recent work on a precise polyethylene with a sulfonic acid group every $21^{\text {st }}$ carbon (p21SA) demonstrated that the 
crystalline backbone resulted in highly organized phase separation from the acid groups. The formation of hydrated layers lined with sulfonate groups led to proton transport comparable to that of Nafion ${ }^{\mathrm{TM}}$, the industry standard for PEMs. ${ }^{10}$ Building upon this finding, we are motivated to design an amorphous, hydrocarbon-based PEM that can achieve a high level of nanophase separation, and thus high proton conductivity. A flexible amorphous backbone, side-group functionalization, and high ion content are characteristics that produce strong nanophase separation in both PFSA and hydrocarbon-based PEMs. ${ }^{1,7,11}$ Furthermore, short side chains and high IEC have also led to enhanced proton dissociation in PEMs. ${ }^{1,3,12}$ All of these are important factors we must consider when designing new polymeric PEMs.

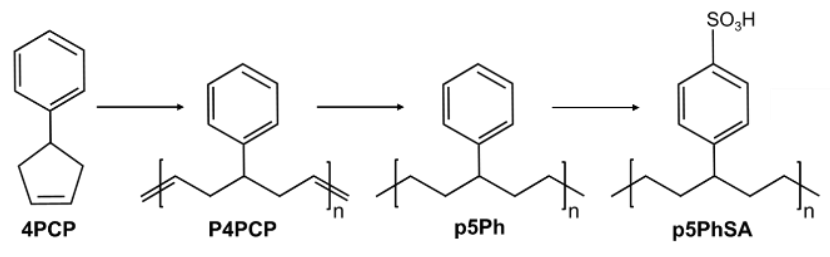

Figure 1. Simplified schematic summarizing intermediate products in the ROMP of 4PCP and its transformation to p5PhSA. Synthetic details can be found in Kendrick, et al. ${ }^{13}$

This study focuses on a novel linear polyethylene with an atactic phenylsulfonic acid pendant group precisely spaced on every $5^{\text {th }}$ carbon, p5PhSA, Figure 1 . This polymer was previously synthesized through ring-opening metathesis polymerization (ROMP) of 4phenylcyclopentene (4PCP), followed by mild hydrogenation of the backbone olefins (> 99\%), and sulfonation of the phenyl rings (95\%). This synthetic route exploits methods currently practiced at the commercial scale. The parent poly(4-phenylcyclopentene) (P4PCP) and its hydrogenated analog $(\mathrm{p} 5 \mathrm{Ph})$ are both amorphous, have a low glass transition temperature $\left(T_{\mathrm{g}} \approx\right.$ $17^{\circ} \mathrm{C}$ ), and are well entangled at the degree of polymerization $(\sim 712)$ used in this study. ${ }^{13-16} \mathrm{We}$ recently investigated $\mathrm{p} 5 \mathrm{PhSA}$ neutralized with a variety of metal cations, and found that in the 
dry state the ions and sulfonate groups strongly nanophase separate from the polymer backbone and self-assemble into percolated ionic aggregates. ${ }^{17} \mathrm{We}$ thus anticipated that p5PhSA would also nanophase separate into hydrophilic and hydrophobic domains. Accessing high proton conductivity with this polymer could lead to a new class of scalable materials for use as PEMs. Furthermore, we envisioned that the high acid concentration, precise spacing of phenylsulfonic acid moieties, and the inherent flexibility of the amorphous parent polymer (p5Ph), could incorporate many of the desired design principles into a new candidate material for rapid proton transport. Due to the short spacer length and high acid content, the ion-exchange capacity (IEC) of p5PhSA is $4.2 \mathrm{mmol} / \mathrm{g}$. This exceeds that of many other PEMs reported in the literature, and is significantly higher than the IEC of typical PFSA membranes, including Nafion 117 (0.91 mmol/ g). ${ }^{1,3,8,9,18-20}$ The glass transition temperature $\left(T_{\mathrm{g}}\right)$ of $\mathrm{p} 5 \mathrm{PhSA}$ is $103{ }^{\circ} \mathrm{C}$, and the thermal degradation temperature $\left(T_{\mathrm{d}}\right)$ is $215{ }^{\circ} \mathrm{C}$, both high enough that p5PhSA may have the thermal and mechanical stability necessary to operate as a PEM. ${ }^{13,17}$ While this $T_{\mathrm{g}}$ is lower than many other hydrocarbon-based PEMs, it may allow for easier processing of p5 PhSA at lower temperatures compared to polymers with phenyl groups in the backbone.

In this paper, we characterize the morphology and proton transport in $\mathrm{p} 5 \mathrm{PhSA}$ for the first time, using a combination of experiments and atomistic molecular dynamics (MD) simulations. The simulations show that $\mathrm{p} 5 \mathrm{PhSA}$ demonstrates strong nanophase separation between the percolated hydrophilic and hydrophobic domains. This nanophase separation and the high ion concentration both lead to excellent proton conductivity (determined experimentally), which exceeds that of Nafion 117 at high water content. The analysis of water dynamics from MD simulations provides further characterization of the pathways for efficient transport in 
p5PhSA. This study introduces p5PhSA as a scalable hydrocarbon-based polymer that exhibits strong nanophase separation and develops design rules for future PEMs.

\section{MATERIALS AND METHODS}

\section{Synthesis and Sample Preparation}

ROMP was used to synthesize P4PCP that features a precise linear polyethylene backbone with a phenyl branch on every fifth carbon. Following quantitative hydrogenation of the backbone olefins, ${ }^{14}$ subsequent sulfuric acid treatment of the polymer produced p5PhSA with $95 \%$ sulfonated repeating units. ${ }^{13}$ The number average degree of polymerization is $\sim 712$ and, based on the repeating unit's formula weight in the sulfonic acid form $\left(224.3 \mathrm{~g} \mathrm{~mol}^{-1}\right)$, equates to a number average molar mass, $M_{\mathrm{n}} \approx 160 \mathrm{~kg} / \mathrm{mol}$. The dispersity, $Đ$, of this sample is $1.7 \pm 0.1$. Temperature modulated differential scanning calorimetry (DSC) indicates a $T_{\mathrm{g}}$ of $103{ }^{\circ} \mathrm{C}$ when dry. ${ }^{17}$ The detailed synthesis and further characterization of the purity of these materials, including thermal gravimetric analysis, size exclusion chromatography, nuclear magnetic resonance (NMR) spectroscopy, and DSC, were reported previously. ${ }^{13}$

Samples were prepared from 2 to 3 weight $\%$ of lyophilized p5PhS polymer dissolved in deionized water. Solutions were drop-cast onto Teflon at $95{ }^{\circ} \mathrm{C}$ and the solvent evaporated to form a polymer film.

The as-cast polymer was hot-pressed at $150{ }^{\circ} \mathrm{C}$ under air, under 1000 psi in a Carver press for 4 hours into a film approximately $400 \mu \mathrm{m}$ thick. The film was then hydrated at $40{ }^{\circ} \mathrm{C}$ and $90 \%$ relative humidity $(\mathrm{RH})$ for $\sim 24$ hours. This as-prepared polymer was stored at room temperature and ambient conditions before experimental measurements.

Nafion 117 was obtained from Sigma-Aldrich (ref. 274674). 


\section{Water Uptake Measurements}

We used a SGA100 Symmetrical Gravimetric Analyzer from VTI Corporation with a Dew point monitor (Edgetech—Dew Prime I) and a Cahn D-200 digital recording balance for the gravimetric water sorption experiments. A $9 \mathrm{mg}$ piece of the as-prepared p5PhSA sample was loaded into the balance and dried at $60{ }^{\circ} \mathrm{C}$ under dry air for 16 hours. Then, the chamber was set to $0 \% \mathrm{RH}$ and $40{ }^{\circ} \mathrm{C}$ and the sample was equilibrated for 6 hours. The humidity was stepped up to each measured relative humidity and the equilibration time was between $3-15$ hours for each step, then weight of the sample was measured. Then the humidity was stepped down similarly, and we used an average of the masses measured on increasing and decreasing humidity. The \% weight gain vs. RH of p5PhA is found in Figure S1. The water uptake was calculated as: ${ }^{10,18,21}$

$$
W U(R H)=\frac{\left(m_{R H}-m_{0}\right)}{m_{0}} \cdot 100 \%
$$

where $W U$ is the $\%$ water uptake, $m_{0}$ is the mass of dry p5PhSA, and $m_{R H}$ is the mass of p5PhSA at a given $\% \mathrm{RH}$.

$\lambda$, the moles of $\mathrm{H}_{2} \mathrm{O}$ per mole of $\mathrm{SO}_{3}{ }^{-}$, (Figure $2 \mathrm{~b}$ ) is calculated as :

$$
\lambda=\frac{\left(m_{R H}-m_{0}\right)}{I E C m_{0} M_{H_{2} O}}
$$

where $M_{\mathrm{H}_{2} \mathrm{O}}$ is the molar mass of water and IEC is the ion-exchange capacity.

\section{Electrochemical Impedance Spectroscopy (EIS)-Proton transport}

Impedance diagrams were measured using a Solartron Analytical Modulab XM MTS spectrometer equipped with a relative humidity chamber, a SM-1.0 bench-top environmental chamber from Thermotron Industries which has a relative humidity range of $10 \%$ to $98 \%$, and a 
temperature range of $-40{ }^{\circ} \mathrm{C}$ to $130{ }^{\circ} \mathrm{C}$. The as-prepared $\mathrm{p} 5 \mathrm{PhSA}$ film was cut into a rectangular strip, then was placed on a glass-slide, with ribbons of stainless steel foil on both ends, which were connected to the frequency analyzer and served as ion-blocking electrodes. This slide-filmelectrode assembly was secured using binder clips. Terminals from the instrument were fed through the chamber wall to access the sample while being able to maintain a humid environment.

This assembly allows for the exposure of the p5PhSA film to the humid environment, and results in an in-plane geometry for sample measurement. At room temperature and atmospheric conditions, the p5PhSA film was approximately $400 \mu \mathrm{m}$ thick, $10 \mathrm{~mm}$ long (distance between the electrodes), and $5 \mathrm{~mm}$ wide. The thickness was measured using a micrometer, and the lateral dimensions were measured by taking a photo of the sample, and measuring the length and width using ImageJ software. These values were then used to calculate the cell constant of the system.

At $40{ }^{\circ} \mathrm{C}$, the sample was equilibrated at $90 \% \mathrm{RH}$, and impedance was measured at every $5 \% \mathrm{RH}$, from $95 \% \mathrm{RH}$ to $25 \% \mathrm{RH}$. The sample was considered to be equilibrated when the measured impedance remained constant (within <1\%) for at least 30 minutes at specific $\%$ RH. The sample was then measured by ramping up the humidity by $5 \%$ increments, to $95 \%$, illustrating excellent reversibility in conductivity (Figure S2). After completing each EIS measurement, the film was removed from the sample chamber and its new dimensions were immediately measured ( $<30$ seconds in atmosphere before measurement complete), to determine the new cell constant under each set of conditions.

The impedance diagrams were fit with an equivalent circuit model to determine the through-plane high-frequency resistance $R$, which is used to calculate the through-plane conductivity, $\sigma=L /(A R)$, where $L$ is the distance between the electrodes and $A$ is the cross- 
sectional area (thickness $\cdot$ width). The same procedure was performed on a Nafion 117 film (180 $\mu \mathrm{m}$ thick at atmospheric conditions), between $30-95 \% \mathrm{RH}$ at $40{ }^{\circ} \mathrm{C}$.

$X$-ray scattering

X-ray scattering was performed on the p5PhSA film at varying relative humidity using the Dual Source and Environmental X-ray Scattering (DEXS) system operated by the Laboratory for Research on the Structure of Matter at the University of Pennsylvania. This Xeuss 2.0 system (Xenocs) with a GeniX3D Cu Ka source (wavelength of $1.54 \AA$ A) was used with sample-todetector distances of $35 \mathrm{~cm}$ and $16 \mathrm{~cm}$ for a total q-range of $\sim 0.4-18 \mathrm{~nm}^{-1}$.

The p5PhSA film was measured inside of a custom environmental chamber, which allows for temperature and humidity control, in order to create the same environment that was present during EIS measurements. ${ }^{22}$ All humidity-controlled X-ray scattering experiments were performed at $40{ }^{\circ} \mathrm{C}$, at varying relative humidity between $0-98 \%$. Equilibration at each humidity was confirmed by performing continuous scans of 5 minutes until the X-ray pattern stabilized. After equilibration, the final X-ray spectrum at each relative humidity was measured. The 2D Xray scattering profiles were azimuthally integrated to 1D data using Foxtrot software.

\section{Computational Methods}

Atomistic MD simulations were conducted using the 2019 GROMACS simulation suite. $^{23-25}$ The system is initialized by generating 216 p5PhSA polymers with eight precise repeat units (monomers), random tacticity, and random sulfonation, such that $95 \%$ of phenyl groups are sulfonated. ${ }^{13}$ All sulfonate groups are assumed to be negatively charged, with all protons dissociated into the water. These protons are included as hydronium ions. Hydronium 
and water molecules are added to the system at random locations using the "gmx insertmolecules"' script. $^{26}$ One hydronium cation is added for each sulfonate anion for overall charge neutrality. Simulations are conducted at a variety of water contents, with the molar ratio of the hydronium and water molecules to the sulfonate groups set to $\lambda=3,4,6,9$, or 12 .

We model the polymer with the bonded and Lennard-Jones OPLS-AA force field ${ }^{27}$ parameters from our previous study, ${ }^{17}$ which are based on the work of Lopes et al. ${ }^{28}$ We also use the dihedral corrections of Siu et al. ${ }^{29}$ Water molecules are modeled using the TIP-4P/2005 water model $^{30}$, and hydronium ions follow the parameters of Sagnella and Voth. ${ }^{31}$ The Lennard-Jones interactions are smoothly shifted to zero at a cutoff of $1.2 \mathrm{~nm}$, and parameters for pairs of unlike atoms are determined from geometric combination rules. Long range electrostatics are calculated using the Particle Mesh Ewald (PME) algorithm ${ }^{32}$ with a cutoff of $1.2 \mathrm{~nm}$ and a Fourier grid spacing of $0.12 \mathrm{~nm}$, which were tuned at runtime to improve efficiency. ${ }^{26}$ Given the aqueous environment to which the ionic groups are confined, we treat polarization in the system using the Molecular Dynamics in Electronic Continuum (MDEC) method. ${ }^{33,34}$ This involves scaling the partial charges of the ionic groups in the system by a constant factor to account for the mean impact of the solvent dielectric, which is not accounted for when ionic partial charges are set to \pm 1 e. In the case of water, this amounts to scaling all partial charges in the sulfonate group and in the hydronium ions by $\frac{1}{\sqrt{\epsilon_{\mathrm{el}}}}=0.75$, where $\epsilon_{\mathrm{el}}$ is the electronic component of the dielectric constant of water. ${ }^{34}$ The SHAKE algorithm is used to replace all harmonic bonds involving hydrogen with constraints. ${ }^{35}$ The system was integrated with a standard leap-frog algorithm and a time step of 2 fs unless otherwise noted. ${ }^{36}$

The system is equilibrated by the same series of NVT and NPT simulations that we have used previously (see the Supporting Information for more details). ${ }^{17,37}$ To maintain a constant 
temperature, we use a stochastic thermostat $(\mathrm{V} \text {-rescale })^{38}$ with a time constant of 0.1 ps. Equilibration runs involving constant pressure steps use the Berendsen barostat ${ }^{39}$ with a time constant of $1 \mathrm{ps}$ and a compressibility of $4.5 \times 10^{-5} \mathrm{bar}^{-1}$. Production runs are conducted in the NVT ensemble at a temperature of $313 \mathrm{~K}\left(40^{\circ} \mathrm{C}\right)$. Runs are conducted for $100 \mathrm{~ns}$ and are repeated eight times with different random sulfonation, tacticity, and initial polymer orientations. Additionally, one run at each water molar fraction is conducted until the hydronium ions have reached the diffusive regime. The $\lambda=3$ system is run for $1 \mu$ s and every other system is run for 500 ns. Analysis of runs, unless otherwise noted, is conducted with custom python scripts that are accelerated using the Numba library and rely on the MDAnalysis library to read the trajectory files. ${ }^{40,41}$

\section{RESULTS AND DISCUSSION}

\section{Water Content and Proton Conductivity}

The water content, $\lambda$ (moles $\mathrm{H}_{2} \mathrm{O} /$ moles $\mathrm{SO}_{3}{ }^{-}$), in p5PhSA was measured at $40{ }^{\circ} \mathrm{C}$ using a sorption balance at $0-90 \%$ relative humidity $(\mathrm{RH})$, Figure 2a. The water content is lower (by $1-2$ moles $\mathrm{H}_{2} \mathrm{O} /$ moles $\mathrm{SO}_{3}{ }^{-}$) in p5PhA than in Nafion 117 at all \% $\mathrm{RH}$, and this difference is slightly larger at higher $\%$ RH. At $90 \% \mathrm{RH}, \lambda \sim 8$ in p5PhSA and $\lambda \sim 10$ in Nafion 117 . The total weight gain at $90 \% \mathrm{RH}$ in p5PSA is $62 \%$ (Figure $\mathbf{S 1}$ ), which is comparable to many other hydrocarbon-based PEMs that have a lower IEC $(0.9-3.6 \mathrm{mmol} / \mathrm{g}) .{ }^{11,18}$ The highly hydrated p5PhSA films remain intact and can be easily handled. In PEMs, the initial water uptake comes from hydrogen bonding adsorption of $\mathrm{H}_{2} \mathrm{O}$ molecules to $\mathrm{SO}_{3} \mathrm{H}$ groups, until a stable hydration shell is formed. ${ }^{1}$ The linear behavior of $\lambda$ with $\mathrm{RH}$ corresponds to thermodynamic sorption and the formation of multiple solvation shells around each $\mathrm{SO}_{3}{ }^{-1}$ Above $50-60 \% \mathrm{RH}$, the rapid 
water uptake in PFSA polymers is due to connected water clusters and growing hydrophilic domains. ${ }^{1}$ We see similar behavior in p5PhS, with a rapid increase in $\lambda$ above $50 \%$ RH (Figure 2a) suggesting the morphology exhibits similar swelling behavior to that in PFSA polymers. The high IEC of p5PhSA $(4.2 \mathrm{mmol} / \mathrm{g})$ indicates significantly more water in $\mathrm{p} 5 \mathrm{PhSA}$ at $\lambda=9$ than in Nafion 117 under the same hydration conditions. Using a $3^{\text {rd }}$ order polynomial, we can estimate $\lambda$ at any $\mathrm{RH}$ at $40{ }^{\circ} \mathrm{C}$, which is particularly useful for comparing the properties of p5PhSA to Nafion 117, as well as for comparing experiments to atomistic MD simulations. ${ }^{1,10}$
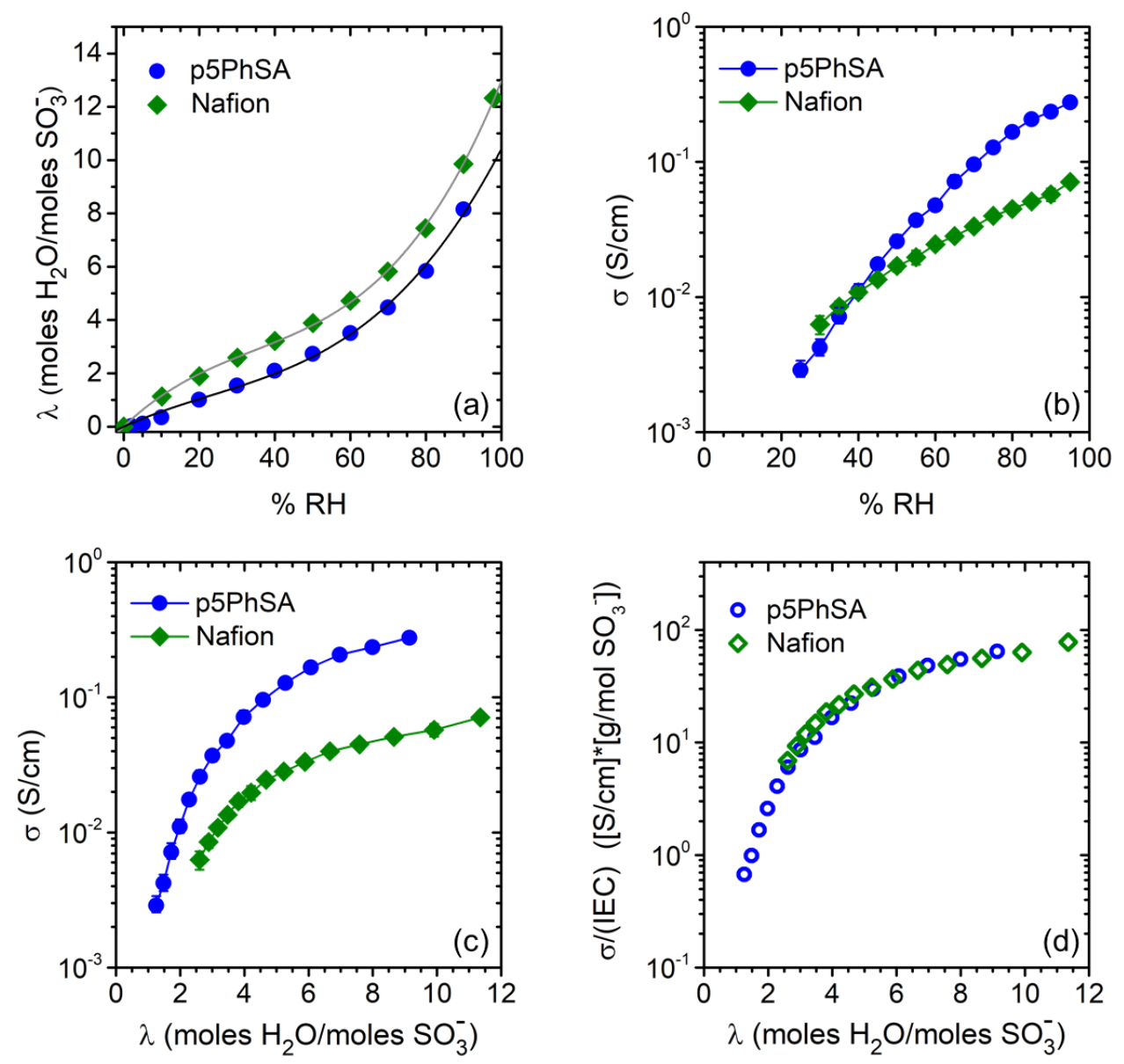

Figure 2. Water uptake and proton conductivity of p5PhSA and of Nafion 117 for comparison. (a) Water uptake $\left(\lambda=\right.$ moles $\mathrm{H}_{2} \mathrm{O}$ /moles $\left.\mathrm{SO}_{3}{ }^{-}\right)$vs. $\%$ relative humidity at $40{ }^{\circ} \mathrm{C}$. Nafion 117 water uptake data is from the literature. ${ }^{1,42}$ Solid lines are fits to a $3^{\text {rd }}$ order polynomial. (b) 
Proton conductivity vs. $\%$ relativity humidity at $40{ }^{\circ} \mathrm{C}$. (c) Proton conductivity vs. water content, $\lambda$, at $40{ }^{\circ} \mathrm{C}$. (d) $\sigma$ normalized by IEC vs. $\lambda$. IEC is the ion content per mass of p5PhSA when $\lambda=0(0.0042 \mathrm{~mol} / \mathrm{g}$ in $\mathrm{p} 5 \mathrm{PhSA}, 0.00091 \mathrm{~mol} / \mathrm{g}$ in Nafion 117).

The proton conductivity, $\sigma$, of p5PhSA shown in Figure $\mathbf{2 b}$ was measured by electrochemical impedance spectroscopy (EIS) at $40{ }^{\circ} \mathrm{C}$ as a function of RH. As a reference, the conductivity for Nafion 117 was measured, and the values are consistent with the literature. ${ }^{9,10,19}$ Below $40 \% \mathrm{RH}$, the proton conductivity of p5PhSA is slightly lower than that Nafion 117, but the conductivity increases significantly in p5PhSA at higher $\mathrm{RH}$. At $40{ }^{\circ} \mathrm{C}$ and $95 \% \mathrm{RH}$, the proton conductivity of p5 PhSA is $0.28 \mathrm{~S} / \mathrm{cm}$, which is 4 times higher than Nafion 117 . Furthermore, the conductivity of p5 $\mathrm{PhSA}$ is higher than that of many other hydrocarbon-based PEMs reported in the literature, both at similar conditions and when other PEMs are at higher temperatures or hydration levels, Figure $\mathbf{S 4} .^{3,8-10,18-20,43}$ The proton conductivity in p5PSA is reversible with increasing and decreasing humidity (Figure S2), as is required for a fuel cell application. The conductivities of p5PhSA and Nafion 117 at $40{ }^{\circ} \mathrm{C}$ are also compared as a function of water content $\lambda$ in Figure 2c; in this representation, p5PhSA outperforms Nafion 117 at all water contents. The short side chains and high IEC apparently contribute to the high conductivity in p5PhSA. When normalized by the IEC, the conductivity of p5PhSA and Nafion 117 are extremely similar at all $\lambda$ (Figure 2d). This suggests that the local proton transport in p5PhSA is similar to that in Nafion 117, perhaps due to similarly strong nanophase separation. Additionally, this emphasizes that the high IEC is a key reason for higher proton conductivity in p5PhSA compared to Nafion 117. The hydrophilic-hydrophobic phase separated morphology is also known to be a critical factor that affects proton conductivity in non-fluorinated hydrocarbons, ${ }^{3,7,12}$ so we next present experiments and MD simulations that reveal the morphology of p5PhSA. 
Morphology of p5PhSA under Humidity: Simulations and Experiments

Atomistic MD simulations were performed for the p5PhSA polymers with eight repeat units per chain. The sulfonic acid groups are assumed to be fully dissociated and the protons are modeled as hydronium ions $\left(\mathrm{H}_{3} \mathrm{O}^{+}\right)$. Using the MD simulations, we characterize the structure of the p5PhSA systems by visualization of configurations and by calculating the total scattering function, $S(q) .{ }^{44}$ Specifically, the simulations enable identification of the self-assembled morphological features over the range of water content from $\lambda=3-12$ at $40{ }^{\circ} \mathrm{C}$. Figure 3 shows snapshots of isodensity surfaces of p5PhA at $\lambda=3$ and $\lambda=9$, with blue hydrophilic domains $\left(\mathrm{SO}_{3}{ }^{-}, \mathrm{H}_{2} \mathrm{O}, \mathrm{H}_{3} \mathrm{O}^{+}\right)$and yellow hydrophobic domains $(\mathrm{C}, \mathrm{H})$. The $\mathrm{MD}$ simulations exhibit percolated hydrophilic domains at $\lambda=3$, consisting of water channels with $\mathrm{SO}_{3}{ }^{-}$groups located at the water-polymer interface. These domains continue to increase in size as the channels swell with increasing water content. The MD isodensity surface snapshots clearly show that the simulated p5PhSA possesses strongly nanophase separated morphologies with hydrophilic and hydrophobic co-continuous domains at all $\lambda=3-12$ (Figure 3, Figure S5).

From the MD simulations we also found that the volume fraction of the hydrophilic domains, $\Phi_{\text {water }}$, increases monotonically with water content; $\Phi_{\text {water }}$ reaches $\sim 47 \%$ at $\lambda=9$, which corresponds to $\sim 95 \% \mathrm{RH}$, the highest experimental value from EIS measurements (Figure 3c). Other hydrocarbon-based PEMs have been reported to have similar or higher $\Phi_{\text {water }}$ that are > $50 \%$ at high $\lambda .^{3}$ However, in Nafion 117 , the $\Phi_{\text {water }}$ under similar conditions is only $\sim 25 \%{ }^{1,45} \mathrm{~A}$ higher degree of swelling in p5PhA is consistent with the higher EIC. Swelling can be a 
drawback in PEMs, since swelling induces stresses that can fracture the membrane or reduce proton conductivity. ${ }^{3}$ Note that the swelling behavior could be reduced and mechanical properties improved by light crosslinking. The co-continuous morphologies revealed by the atomistic MD simulations are highly advantageous, because the hydrophobic domain prevents the polymer from dissolving, while the continuous water nanodomain facilitates efficient proton transport.
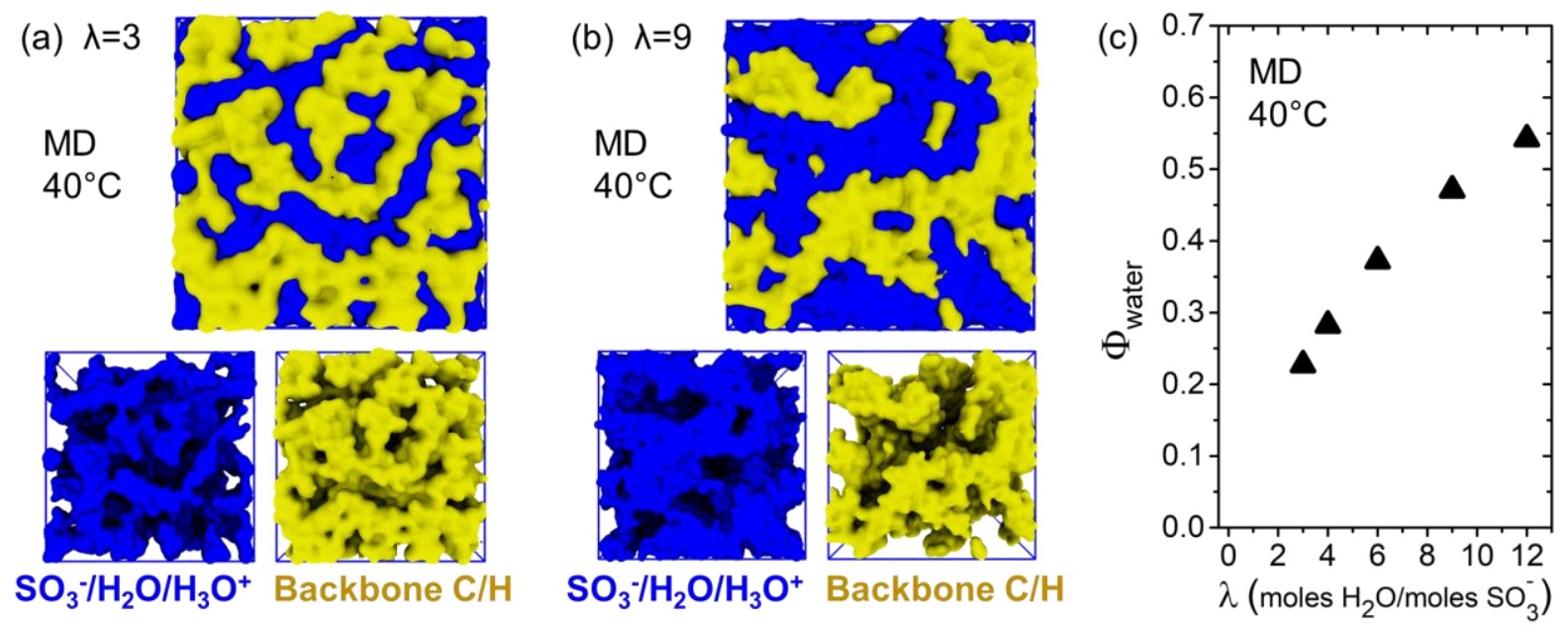

Figure 3. Atomistic molecular dynamics simulation results. Snapshots of isodensity surfaces of p5PhSA at (a) $\lambda=3$ (box edge $8.7 \mathrm{~nm}$ ) and (b) $\lambda=9$ (box edge $9.8 \mathrm{~nm}$ ) at an isodensity of 0.3. These and all other snapshots were rendered using VMD and Tachyon ray tracing, with atomic radii set based on the by the Van der Waals radius of the atom species. ${ }^{46-48}$ The hydrophilic domains are shown in blue and the hydrophobic domains in yellow. These co-continuous nanophases are shown together (top) and separately (bottom). (c) Volume fraction of water including $\mathrm{H}_{3} \mathrm{O}^{+}$vs. water content.

In situ X-ray scattering measurements were performed at $40{ }^{\circ} \mathrm{C}$ as a function of $\mathrm{RH}$ on a p5 PhSA film to characterize the morphology. The experimental scattering results exhibit broad amorphous peaks centered at $q \sim 12.5 \mathrm{~nm}^{-1}$ and peaks at $q_{1}^{\text {Exp }} \sim 2-3 \mathrm{~nm}^{-1}$, resulting from the strong nanophase separation that produces ionic aggregates (Figure 4a). Even in the dry condition, a strong aggregate peak is evident, because the morphology is highly uniform due to 
the precise spacing of the acid groups along the polymer backbone ${ }^{49-52}$ and due to the high contrast of scattering length densities between $\mathrm{SO}_{3}{ }^{-}$groups and hydrocarbon domains. The aggregate peak at $q_{1}^{\text {Exp }}$ shifts to lower $q$ with increasing $\lambda$, which indicates swelling of the hydrophilic domains with water. The widths of the $q_{1}^{\text {Exp }}$ peaks do not significantly broaden with water content, with the full width at half maximum (FWHM) $\Delta q_{1}^{\text {Exp }} \sim 0.6-0.9 \mathrm{~nm}^{-1}$ for all systems with sufficient contrast to produce a scattering peak. These FWHMs give quantitative information concerning the uniformity of the correlation lengths of the aggregate morphologies and indicate that the uniformity is relatively constant with $\lambda$ in these precise polymers. With increasing $\lambda$, the intensity of the $q_{1}^{\text {Exp }}$ peak decreases, disappears at $\lambda=8$, and reappears at $\lambda=10$. As detailed below and described previously for sulfonated Diels Alder polyphenylenes (SDAPP), ${ }^{18}$ the changing intensity of $q_{1}^{\text {Exp }}$ is associated with changes in the scattering contrast between the hydrophilic and hydrophobic nanoscale domains, rather than with a loss of the cocontinuous morphology. In short, the absence of the $q_{1}^{\text {Exp }}$ peak at $\lambda=8$ suggests that at this water content there is a minimum scattering contrast between the hydrophobic and hydrophilic domains.

p5PhSA also exhibits a higher order peak at $q_{2}^{\operatorname{Exp}}\left(\sim 4-6 \mathrm{~nm}^{-1}\right)$, which is broader and shifts to lower $q$ as $\lambda$ increases without decreasing in intensity. In PFSA polymers, a second low$q$ peak has been attributed to various structural features such as the width of the water channel or the distance separating $\mathrm{SO}_{3}{ }^{-}$groups. ${ }^{7,45}$ In Figure 4a the second peak could have a similar origin or be a higher order peak of $q_{1}^{\text {Exp }}$, although future work is required to resolve the origin of the peak at $q_{2}^{\text {Exp }}$ in p5PhSA. 

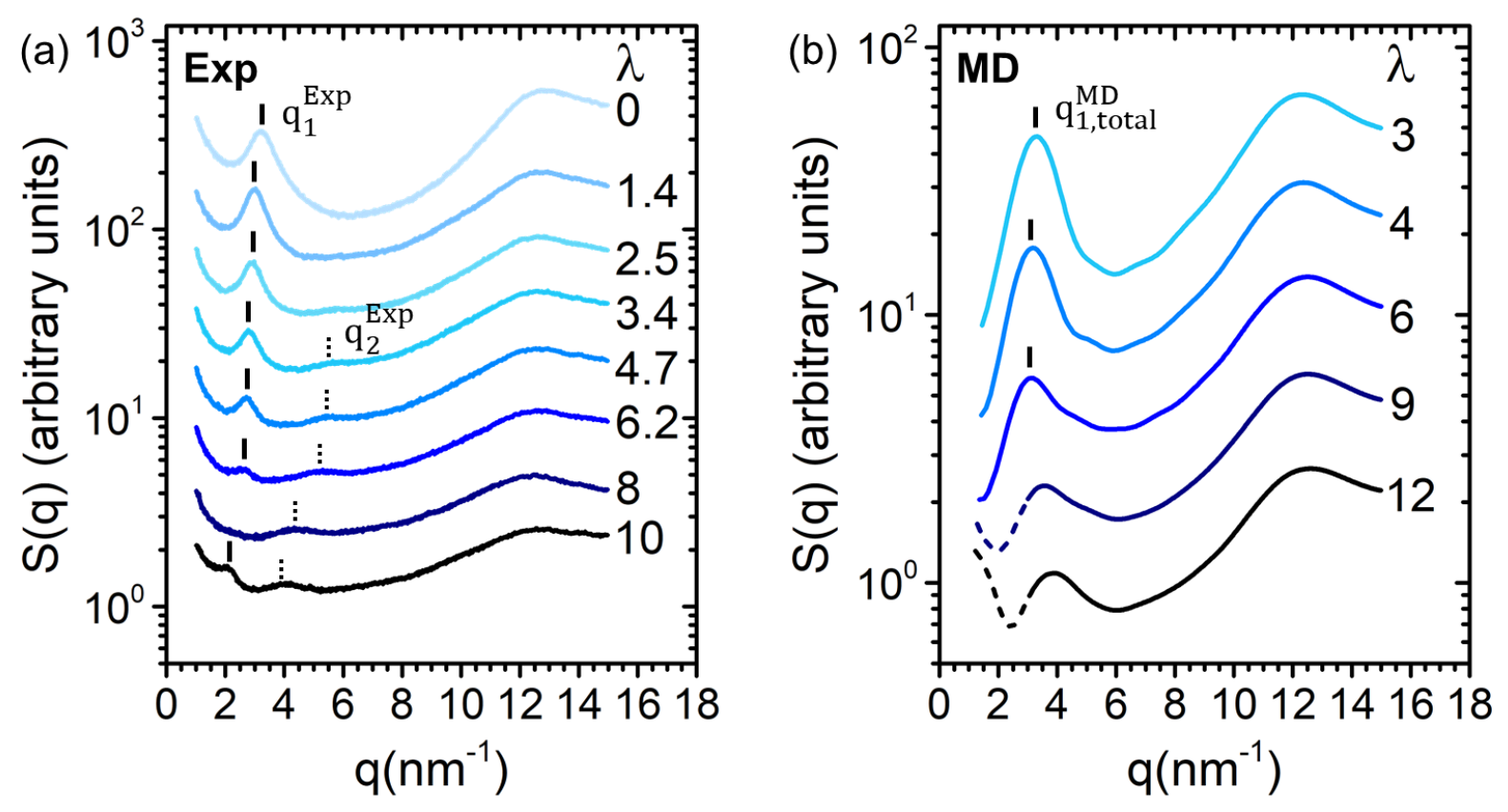

Figure 4. Scattering results from experiments and simulations as a function of water content for p5PhSA at $40{ }^{\circ} \mathrm{C}$. (a) X-ray scattering data measured under controlled relative humidity conditions: $\lambda=0,1.4,2.5,3.4,4.7,6.2,8$, and 10 correspond to $0 \%, 28 \%, 48 \%, 60 \%, 71 \%, 81 \%$, $90 \%$, and $98 \%$ RH. (b) Total scattering function from MD simulations for $\lambda=3,4,6$, 9, and 12 . Data in (a) and (b) are shifted vertically.

To complement the experimental X-ray scattering data and provide insight into the behavior of $\mathrm{p} 5 \mathrm{PhSA}$, we further analyze the atomistic MD simulations by computing the total scattering function following the procedure detailed in the Supporting Information. There is significant qualitative agreement between the experiments and the total scattering from MD (Figure 4b). Consistent with the experiments, the simulations exhibit an amorphous peak at $q \sim$ $12.5 \mathrm{~nm}^{-1}$ at all water contents. The simulations also exhibit a lower $q$ peak at $q_{1, \text { total }}^{\mathrm{MD}}$, which has a position and intensity that decreases as $\lambda$ increases from 3 to 6 , similar to the behavior of $q_{1}^{\operatorname{Exp}}$ in the experimental results. As described next, the apparent lack of agreement in the experimental and simulated scattering functions at higher water contents can be attributed to the increased 
sensitivity of the low $q$ scattering features associated with minor variations in the mass densities from the MD simulations.

The full scattering function that is plotted in Figure $4 \mathrm{~b}$ can be decomposed into six partial scattering terms,

$$
S_{\text {total }}(q)=S_{p p}+S_{s s}+S_{w w}+S_{w p}+S_{s p}+S_{w s}
$$

where $S_{\mathrm{pp}}$ is the scattering between $\mathrm{C}$ and $\mathrm{H}$ atoms in the polymers, $S_{\mathrm{ss}}$ is the scattering between the atoms in the $\mathrm{SO}_{3}{ }^{-}$groups, and $S_{\mathrm{ww}}$ is the scattering between the atoms in the water and hydronium ions. There are also three cross terms: $S_{\mathrm{wp}}$ for atoms in $\mathrm{H}_{2} \mathrm{O} / \mathrm{H}_{3} \mathrm{O}^{+}$and polymer, $S_{\text {sp }}$ for atoms in $\mathrm{SO}_{3}{ }^{-}$and polymer, and $S_{\mathrm{ws}}$ for atoms in $\mathrm{H}_{2} \mathrm{O} / \mathrm{H}_{3} \mathrm{O}^{+}$and $\mathrm{SO}_{3}{ }^{-}$. Note that $S_{\mathrm{wp}}$ exhibits a large negative value, and the amplitudes of the partial scattering functions exceed that of $S_{\text {total }}$, Figure 5. Thus, small variations in the simulations (mass density, force fields, and equilibration) can produce significant changes in $S_{\text {total }}$ particularly at high $\lambda$ due to subtle cancellation effects in the terms in Equation (3), and this impedes rigorous comparisons with experimental scattering results. In recognition of this limitation at $\lambda=9$ and 12 , the $S_{\text {total }}$ data at $q<3 \mathrm{~nm}^{-1}$ is represented by a dashed line in Figure $\mathbf{4 b}$. We reported a similar limitation in our study of sulfonated Diels Alder polyphenylene (SDAPP). ${ }^{18}$ 

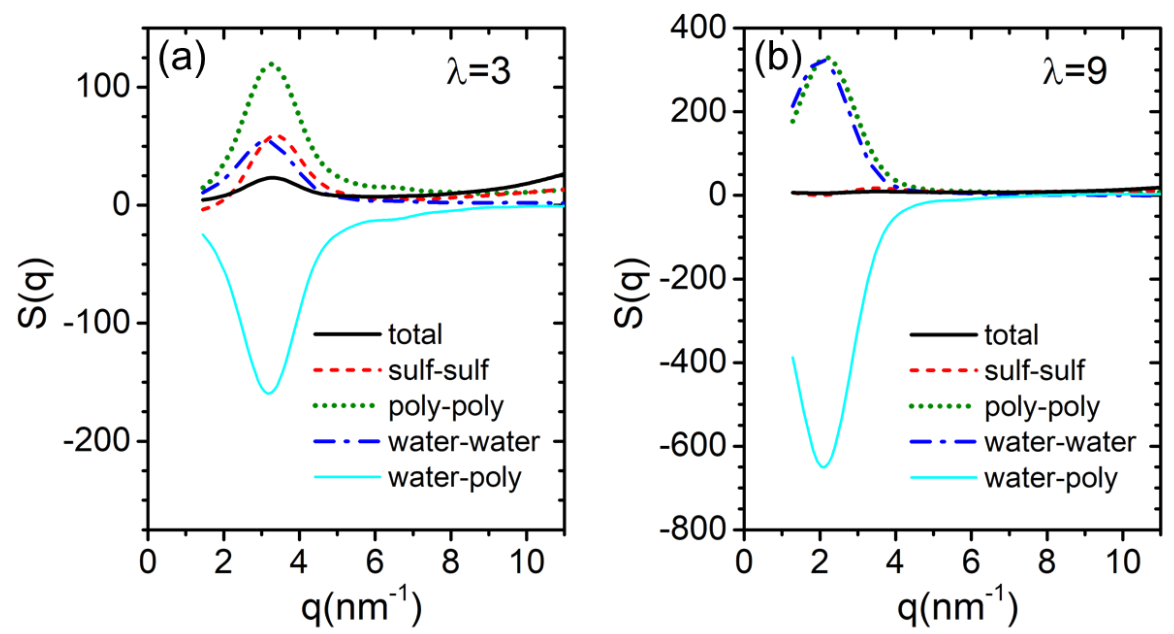

Figure 5. Four of the partial scattering functions from p5PhSA MD simulations at (a) $\lambda=3$ and (b) $\lambda=9$ at $40{ }^{\circ} \mathrm{C}$. Notice that the $S(q)$ scale is larger in part (b). Plots for all $\lambda$ and including the two additional partial scattering functions, $S_{\mathrm{sp}}$ and $S_{\mathrm{ws}}$, are provided in Figure S7. The total scattering function (black) is the sum of the six partial scattering functions.

While $S_{\text {total, }}$ as well as the experimental $S(q)$, can be difficult to interpret directly due to changes in the electron density contrast with increasing water content, the partial scattering functions from MD simulations clearly demonstrate nanophase separation at all water contents. With increasing $\lambda$, the values of $q_{1, \mathrm{pp}}^{\mathrm{MD}}, q_{1, \mathrm{ww}}^{\mathrm{MD}}$, and $q_{1, \mathrm{wp}}^{\mathrm{MD}}$ decrease smoothly indicating a continuous increase in the characteristic distance between water channels, Figure 6a (see also Figure S8). Interestingly, the trend in $q_{1, \mathrm{ww}}^{\mathrm{MD}}$ correlates well with the trend in $q_{1}^{\text {Exp }}$ from the X-ray scattering results. This is seen in Figure $\mathbf{6 b}$, which shows the characteristic lengths $d=2 \pi / q$, with $d_{1}^{\text {Exp }}$ increasing from 1.9 to $3.1 \mathrm{~nm}$ with increasing $\lambda$ and $d_{1, \mathrm{ww}}^{\mathrm{MD}}$ having similar values. $d_{1, \mathrm{ww}}^{\mathrm{MD}}$ is approximately consistent with the intra-aggregate spacing of the hydrophilic domains in Figure 3. 

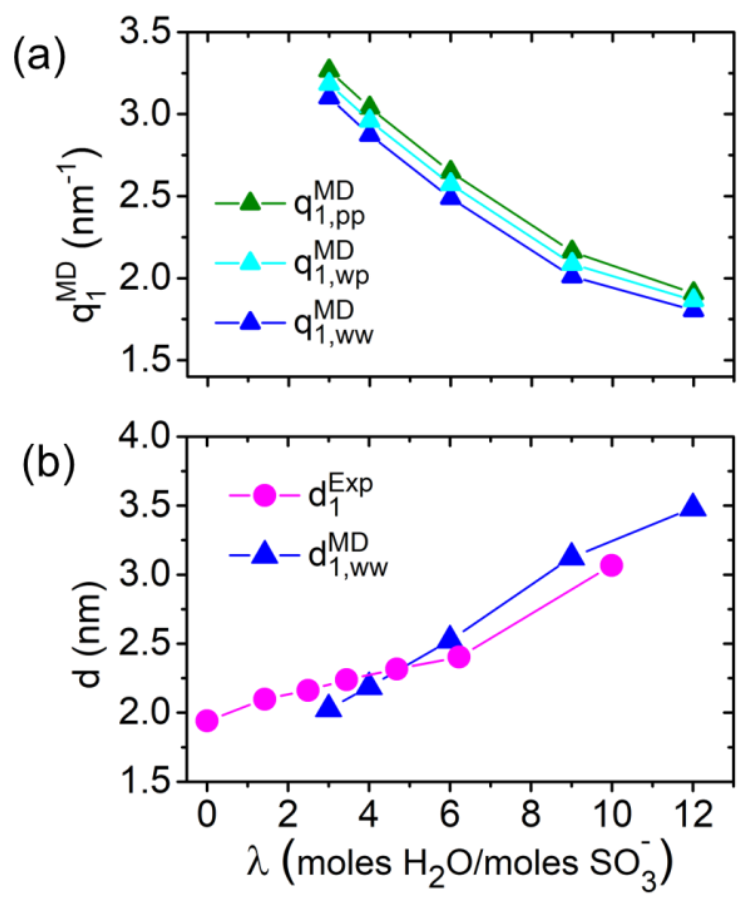

Figure 6. Scattering results from MD simulations and experiments. (a) Scattering peak positions from three partial scattering functions $\left(q_{1, \mathrm{pp}}^{\mathrm{MD}}, q_{1, \mathrm{ww}}^{\mathrm{MD}}, q_{1, \mathrm{wp}}^{\mathrm{MD}}\right)$ vs. water content. (b) Characteristic lengths $d_{1, \mathrm{ww}}^{\mathrm{MD}}$ associated with the hydrophilic domains in the MD simulations and characteristic lengths $d_{1}^{\text {Exp }}$ from the aggregate peak in the X-ray scattering.

To explore the shapes of the hydrophilic domains with increasing $\lambda$, we compute local, minimal cross-sectional areas to quantify the breadth of the water channels. This is defined by the plane of minimal area that passes through a given oxygen atom and is fully contained within the aqueous region; see the Supporting Information for details. The cross-sectional area of the water channel is computed for every oxygen atom in the system and a frequency distribution of observed cross sectional areas is reported in Figure 7. The area under the frequency distribution over a range of cross-sectional areas corresponds to the fraction of the total number of oxygen atoms that are contained in that range of channel sizes. The frequency distribution of the local cross-sectional areas broadens and shifts to higher values with increasing $\lambda$, Figure 7. At $\lambda=3$ the distribution exhibits a sharp peak near $0.9 \mathrm{~nm}^{2}$ that rapidly falls off for larger areas, 
indicating fairly uniform nanoscale confinement within the water channels, with a mean and standard deviation of $0.9 \pm 0.5 \mathrm{~nm}^{2}$. As water content increases, the distribution of areas broadens to larger local cross-sectional areas while the local maximum in the frequency distribution shifts toward $2 \mathrm{~nm}^{2}$. At the highest water content, $\lambda=12$, the local cross-sectional areas span from $1 \mathrm{~nm}^{2}$ to $>15 \mathrm{~nm}^{2}$, with a mean and standard deviation of $7.8 \pm 1.7 \mathrm{~nm}^{2}$, indicating both less overall confinement than at lower $\lambda$ and a wide distribution of local confinement. The persistence of local cross-sectional areas $<3 \mathrm{~nm}^{2}$ suggests that even at high water contents, there are local regions with small cross-sectional areas within the hydrophilic domains that might slow locally water and proton transport. The increase in local cross-sectional area with increasing $\lambda$ correlates with the conductivity measurements, Figure $2 \mathrm{~b}$. The distribution of areas observed in Figure 7 is larger than what may be expected upon visual inspection of the isodensity surfaces from Figure 3. This may be explained in part by small differences in length scales observed in Figure 3 leading to larger differences in cross section-areas when squared. Further, as Figure 7 is illustrative of the channel size of the "average" oxygen atom in the system, cross-sections of larger area will be more heavily weighted since they contain more atoms.

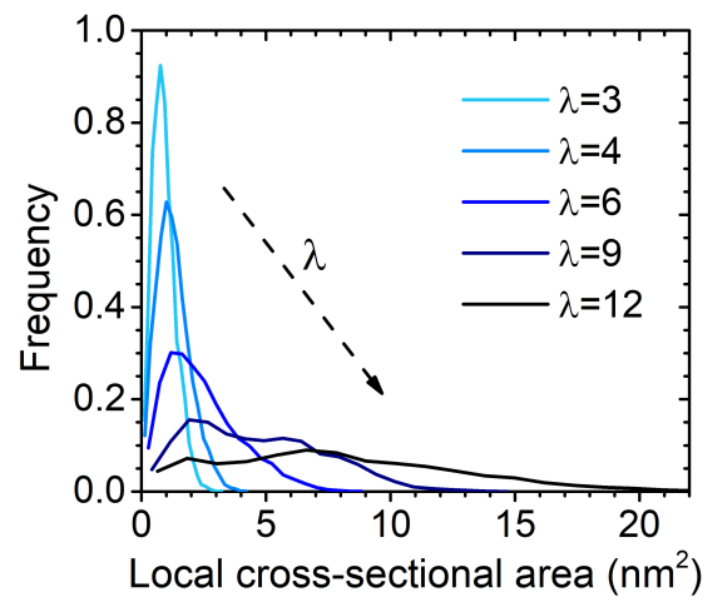


Figure 7. Frequency distribution for the local cross-sectional areas of the aqueous domains surrounding each oxygen atom, for each $\lambda$. The area under the curve for a range of crosssectional areas gives the fraction of oxygen atoms that exist in that range of channel sizes. The mean \pm standard deviation of each of these distributions is: $\lambda=3,0.9 \pm 0.5 \mathrm{~nm}^{2} ; \lambda=4,1.3 \pm 0.6$ $\mathrm{nm}^{2} ; \lambda=6,2.4 \pm 1.0 \mathrm{~nm}^{2} ; \lambda=9,4.6 \pm 1.2 \mathrm{~nm}^{2} ;$ and $\lambda=12,7.8 \pm 1.7 \mathrm{~nm}^{2}$.

Finally, we investigate the local environment of the hydronium ions in the MD simulations. The $\mathrm{H}_{3} \mathrm{O}^{+}$ions in PEMs coordinate via $\mathrm{H}$-bonding with neighboring water molecules and $\mathrm{SO}_{3}{ }^{-}$groups. From our $\mathrm{MD}$ simulations we calculate the distribution of the number of oxygen atoms in $\mathrm{SO}_{3}{ }^{-}$groups $\left(N_{\mathrm{Os}}\right)$ and in water molecules $\left(N_{\mathrm{Ow}}\right)$ that are coordinated with each $\mathrm{H}_{3} \mathrm{O}^{+}$ion, Figure 8 and Figure S11; see Supporting Information for details. From these distributions, we obtain the average oxygen coordination number of the hydronium ions, which is nearly constant with $\lambda$, even though there is a change in the dominant coordinating species. At $\lambda=3$, the average oxygen coordination number of the hydronium ions is $5.5 \pm 1.7$, with a preference for coordination with $\mathrm{SO}_{3}{ }^{-}$groups. Upon increasing the water content to $\lambda=9$, the average oxygen coordination number is relatively unchanged at $5.7 \pm 1.7$, although now water coordination is strongly preferred. As expected, swelling with water leads to greater $\mathrm{H}_{3} \mathrm{O}^{+}$ solvation by water molecules. Additionally, at $\lambda=9$ many of the $\mathrm{H}_{3} \mathrm{O}^{+}$are not coordinated to any $\mathrm{SO}_{3}{ }^{-}$groups $\left(N_{\mathrm{Os}}=0\right)$, indicating that hydronium ions are surrounded by at least one water solvation shell. This hydronium coordination behavior for p5PhSA is qualitatively similar to that found previously for SDAPP with quantitative differences probably arising from the greater backbone flexibility of p5PSA. ${ }^{53}$ Overall, the observed solvation of $\mathrm{H}_{3} \mathrm{O}^{+}$by neighboring water molecules is critical for rapid proton transport, because this leads to more bulk-like motion of the water molecules, as well as more hopping sites for the proton to travel via the Grotthuss mechanism. 
(a)

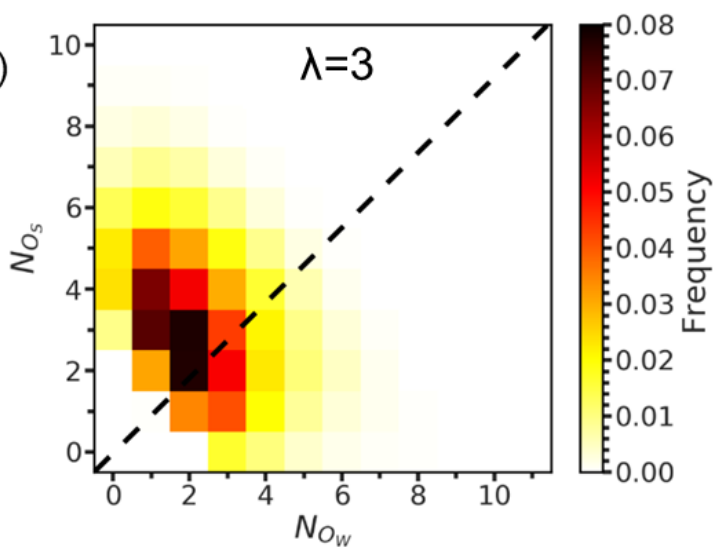

(b)

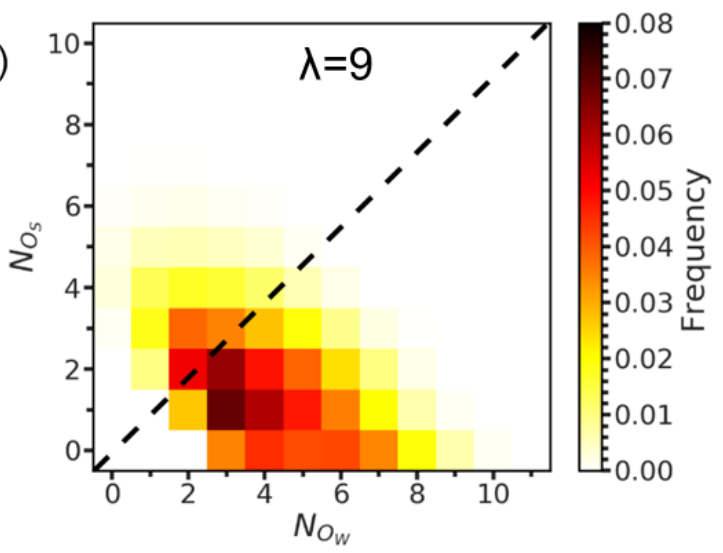

Figure 8. Probability distributions for (a) $\lambda=3$ and (b) $\lambda=9$ of coordination of $\mathrm{H}_{3} \mathrm{O}^{+}$ molecules with the number of oxygens in $\mathrm{SO}_{3}{ }^{-}\left(N_{\mathrm{Os}}\right)$ and oxygens in water $\left(N_{\mathrm{Ow}}\right)$. The dashed line indicates an equal probability. Distributions for all $\lambda$ can be found in Figure S11.

Water and Hydronium Dynamics from Atomistic MD Simulations

In addition to the structural information discussed above, we use the MD simulations to study the dynamics of water in p5PhSA. While the simulations do not account for the Grotthuss mechanism, the MD simulations capture the vehicular water and hydronium dynamics. We calculate the translational diffusion coefficient for the water molecules, $D_{\mathrm{H}_{2} \mathrm{O}}^{\mathrm{MD}}$, from their mean squared displacements. All the systems simulated $(\lambda \geq 3)$ have percolated hydrophilic domains and have well-defined diffusion coefficients (Figure S15). We also extract the average water rotational time, $\tau_{\mathrm{H}_{2} \mathrm{O}}^{\mathrm{MD}}$, which is affected by confinement and proximity to the sulfonate groups. Water rotation is an intrinsic part of water dynamics, because as a water molecule switches $\mathrm{H}$ - 
bonds with its neighbors it must rotate. We plot these values normalized by their corresponding simulated values in bulk water $\left(\left(\tau^{-1}\right)_{\mathrm{H}_{2} \mathrm{O}}^{\mathrm{MD}} /\left(\tau^{-1}\right)_{\mathrm{H}_{2} \mathrm{O}-\mathrm{Bulk}}^{\mathrm{MD}}\right.$ and $\left.D_{\mathrm{H}_{2} \mathrm{O}}^{\mathrm{MD}} / D_{\mathrm{H}_{2} \mathrm{O}-\mathrm{Bulk}}^{\mathrm{MD}}\right)$ as a function of $\lambda^{-}$ 1 , the inverse of the water content, which describes the confinement level of the water molecules, ${ }^{54}$ Figure 9. We also include data from a previously simulated sulfonated polymer, p21SA. The polymer p21SA was simulated in both the crystalline state, which forms layered hydrophilic domains, and in the amorphous state, which forms a disordered percolated water network. $^{10}$

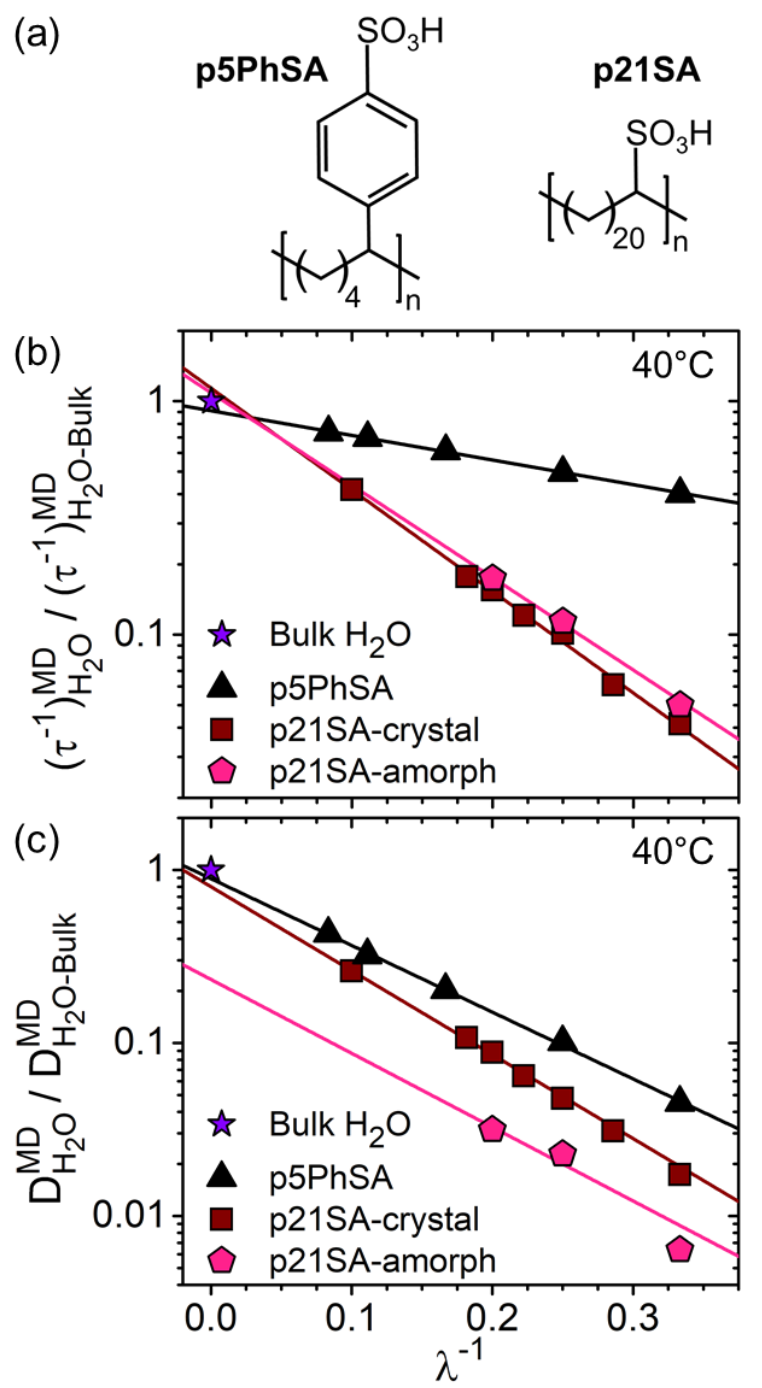

Figure 9. Water dynamics from $\mathrm{MD}$ simulations at $40{ }^{\circ} \mathrm{C}$. (a) Schematics of p5PhSA 
(IEC=4.2 $\mathrm{mmol} / \mathrm{g}$ ) and p21SA (IEC=2.7 $\mathrm{mmol} / \mathrm{g})$. (b) Rotational frequency, $\left(\tau^{-1}\right)_{\mathrm{H}_{2} \mathrm{O}}^{\mathrm{MD}}$ normalized by the bulk water value for p5PSA and both crystalline and amorphous p21SA. ${ }^{10}$ (c) Diffusion coefficient of $\mathrm{H}_{2} \mathrm{O}, D_{\mathrm{H}_{2} \mathrm{O}}^{\mathrm{MD}}$, normalized by the bulk water diffusion coefficient. Data for $\mathrm{p} 21 \mathrm{SA}$ is from the literature. ${ }^{10}$

Both $\left(\tau^{-1}\right)_{\mathrm{H}_{2} \mathrm{O}}^{\mathrm{MD}}$ and $D_{\mathrm{H}_{2} \mathrm{O}}^{\mathrm{MD}}$ values for p5PhSA extrapolate to the corresponding values in bulk $\mathrm{H}_{2} \mathrm{O}$ at $\lambda^{-1}=0$ and exhibit an exponential decay with $\lambda^{-1}$. The slower water dynamics with decreasing water content is consistent with the motion of the water molecules being slowed by nanoscale confinement effects and by the attractions to the sulfonate-lined edges of the water channels. Conversely, as water content increases, a higher fraction of the water molecules will exhibit bulk-like behavior. While crystalline p21SA has water layers and amorphous p21SA has percolated water channels, their $\left(\tau^{-1}\right)_{\mathrm{H}_{2} \mathrm{O}}^{\mathrm{MD}}$ values are similar and extrapolate to $\left(\tau^{-1}\right)_{\mathrm{H}_{2} \mathrm{O}-\text { bulk }}^{\mathrm{MD}}$. However, the slope of $\left(\tau^{-1}\right)_{\mathrm{H}_{2} \mathrm{O}}^{\mathrm{MD}}$ vs. $\lambda^{-1}$ is 4 times steeper for the p21SA systems than for p5PhSA. We attribute this to the difference in IEC and overall volume of water in the system: the IEC is $2.7 \mathrm{mmol} / \mathrm{g}$ for $\mathrm{p} 21 \mathrm{SA}$ and $4.2 \mathrm{mmol} / \mathrm{g}$ for $\mathrm{p} 5 \mathrm{PhSA}$. Thus, $\mathrm{p} 5 \mathrm{PhSA}$ contains more water at a given $\lambda$ resulting in a higher fraction of bulk-like behavior. By taking the square root of the local cross-sectional area distributions, we can estimate the mean width of the percolated channels in p5PhSA, approximately $1.0-2.1 \mathrm{~nm}$ for $\lambda=3-9$. This is larger than the thicknesses of the hydrated layers in p21SA, which range from $0.5-1.4 \mathrm{~nm}$ for $\lambda=3-10,{ }^{10}$ and is further evidence that the shallow slope of $\left(\tau^{-1}\right)_{\mathrm{H}_{2} \mathrm{O}}^{\mathrm{MD}}$ in $\mathrm{p} 5 \mathrm{PhSA}$ is primarily a result of higher volume of water in the system. Similarly, we attribute the faster water diffusion, $D_{\mathrm{H}_{2} \mathrm{O}}^{\mathrm{MD}}$, found in $\mathrm{p} 5 \mathrm{PhSA}$ to larger amount of water. In addition, both p5PhSA and crystalline p21SA have $D_{\mathrm{H}_{2} \mathrm{O}}^{\mathrm{MD}}$ values that extrapolate to the diffusion coefficient of bulk $\mathrm{H}_{2} \mathrm{O}$ at $\lambda^{-1}=0$. Several experimental studies of 
Nafion have also shown water diffusion coefficients that extrapolate to the bulk water diffusion coefficient with increasing water content. ${ }^{1,55}$ However, $D_{\mathrm{H}_{2} \mathrm{O}}^{\mathrm{MD}}$ in amorphous p21SA does not extrapolate to the bulk $\mathrm{H}_{2} \mathrm{O}$ value, which was attributed to nonuniformity and constrictions in the water channels. ${ }^{10}$ This suggests that although $\mathrm{p} 5 \mathrm{PhSA}$ is also amorphous, it may have a greater uniformity in its water channels than does amorphous p21SA. Furthermore, the faster water dynamics in $\mathrm{p} 5 \mathrm{PhSA}$ relative to p21SA in the atomistic MD simulations is consistent with p5 PhSA having higher proton conductivity than p21SA experimentally, $0.28 \mathrm{~S} / \mathrm{cm}$ for $\mathrm{p} 5 \mathrm{PhSA}$ as compared with $0.09 \mathrm{~S} \mathrm{~cm}^{-110}$ for p21SA at $40{ }^{\circ} \mathrm{C}$ and $95 \% \mathrm{RH}$.

To compare the proton transport between simulations and experiments, we use the hydronium diffusion coefficient from the MD simulations, $D_{\mathrm{H}_{3} \mathrm{O}^{+}}^{\mathrm{MD}}$, and the proton diffusion coefficient calculated from the experimental conductivity, $D_{\sigma}^{\mathrm{Exp}}$. While $D_{\mathrm{H}_{3} \mathrm{O}^{+}}^{\mathrm{MD}}$ only includes vehicular transport and proton association with $\mathrm{SO}_{3}^{-}$groups, $D_{\sigma}^{\mathrm{Exp}}$ also includes the Grotthuss mechanism. We define $D_{\sigma}^{\text {Exp }}$ using the Nernst-Einstein: ${ }^{18,55}$

$$
D_{\sigma}^{\mathrm{Exp}}=\Lambda \frac{R T}{z^{2} F^{2}}
$$

where $\Lambda$ is the volumetric molar conductivity, $z$ is the charge of an electron, $F$ is Faraday's constant, and $R$ is the gas constant. The molar volume was determined from the simulations, using a density of dry p5PhSA of $1.28 \mathrm{~g} \cdot \mathrm{cm}^{-3}$. We note that while the Nernst-Einstein equation is only rigorously valid in dilute and homogeneous solutions of ionic salts, it is commonly used to describe water and ion transport in proton exchange membranes, ${ }^{1}$ as we do here with $\mathrm{p} 5 \mathrm{PhSA}$. Additionally, note that the MD simulations have reached the diffusive regime for the hydronium diffusion with $D_{\mathrm{H}_{3} \mathrm{O}^{+}}^{\mathrm{MD}}$ calculated over $0.25 \mu$ s, and the conductivity plateau in the EIS 
measurements occurs around $3 \times 10^{5} \mathrm{~Hz}$, corresponding to a time scale of $3 \mu$ s, so these two measures of proton transport probe similar time scales.

Due to slight differences in the bulk diffusion coefficient of $\mathrm{H}_{2} \mathrm{O}$ in the experiments and in the MD simulations $\left(3.2 \times 10^{-5} \mathrm{~cm}^{2} \mathrm{~s}^{-1}\right.$ and $2.9 \times 10^{-5} \mathrm{~cm}^{2} \mathrm{~s}^{-1}$ at $40{ }^{\circ} \mathrm{C}$, respectively), we normalize $D_{\sigma}^{\text {Exp }}$ and $D_{\mathrm{H}_{3} \mathrm{O}^{+}}^{\mathrm{MD}}$ by the bulk water diffusion coefficient, Figure $10 .{ }^{56} D_{\mathrm{Bulk} \mathrm{H}_{2} \mathrm{O}}^{\mathrm{MD}}$ was calculated from a 20 ns simulation containing $~ 6000$ water molecules and $D_{\mathrm{Bulk}_{2} \mathrm{O}}^{\text {Exp }}$ was obtained from the literature. ${ }^{57}$ The diffusion coefficients exhibit similar qualitative behavior, with a steeper slope at lower water content. However, $D_{\sigma}^{\mathrm{Exp}}$ is larger than $D_{\mathrm{H}_{3} \mathrm{O}^{+}}^{\mathrm{MD}}$ at all water contents, which is consistent with the Grotthuss mechanism being present only in the experiments and leading to faster proton diffusion compared to pure vehicular transport. ${ }^{1,3-6}$ Similarly, the fact that $D_{\sigma}^{\text {Exp }}$ is higher than $D_{\mathrm{H}_{3} \mathrm{O}^{+}}^{\mathrm{MD}}$ or $D_{\mathrm{H}_{2} \mathrm{O}}^{\mathrm{MD}}$, as a result of the Grotthuss mechanism, has been previously found in Nafion as well as in p21SA. ${ }^{10,18,55,58}$ In this study, the comparison of $D_{\sigma}^{\text {Exp }}$ and $D_{\mathrm{H}_{3} \mathrm{O}^{+}}^{\mathrm{MD}}$ provides additional confidence of faster proton transport in $\mathrm{p} 5 \mathrm{PhSA}$ compared to Nafion or p21SA.

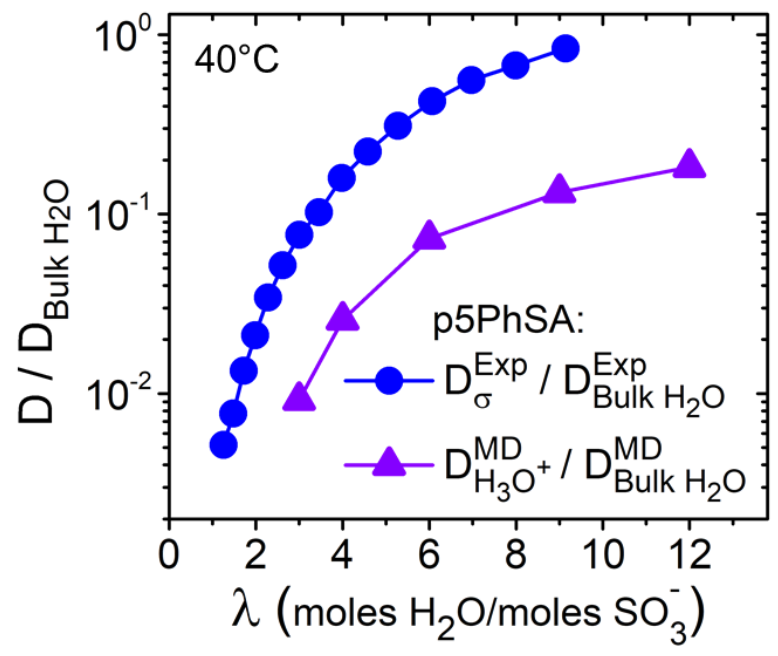


Figure 10. Normalized experimental proton conductivity diffusion coefficient $D_{\sigma}^{\text {Exp }}$ and normalized $\mathrm{H}_{3} \mathrm{O}^{+}$diffusion from $\mathrm{MD}$ simulations $D_{\mathrm{H}_{3} \mathrm{O}^{+}}^{\mathrm{MD}}$ in $\mathrm{p} 5 \mathrm{PhSA}$.

Overall, the water dynamics in our MD simulations indicate that the strong nanoscale phase separation in hydrated $\mathrm{p} 5 \mathrm{PhSA}$ is consistent with the experimentally observed high proton conductivity. As the characteristic size of the co-continuous hydrophilic domains $d{ }_{1, \mathrm{ww}}^{\mathrm{MD}}$ and the mean local cross-sectional area both increase with increasing water content, the water dynamics tend toward bulk behavior. This is because more water molecules are locally surrounded by water molecules rather than by the sulfonate groups at the hydrophilic / hydrophobic interface. Thus, the changes in water dynamics and nanoscale morphology are consistent with one another.

\section{CONCLUSIONS}

Using a combination of experiments and atomistic MD simulations, we characterized the nanoscale morphology and water and proton dynamics in $\mathrm{p} 5 \mathrm{PhSA}$, a precise polymer synthesized by ROMP and post-polymerization modifications. There is strong nanophase separation between the percolated hydrophobic and hydrophilic domains in $\mathrm{p} 5 \mathrm{PhSA}$, a morphology that has previously been a challenge to achieve in hydrocarbon-based PEMs. We attribute this co-continuous morphology to the unique combination of a flexible, all-carbon polyethylene backbone and phenylsulfonic acid branches. While the precision of p5 $\mathrm{PhSA}$ is highly advantageous for experimental and simulation studies, similar chemistries with nonprecise architectures may also produce strongly segregated and co-continuous self-assembled morphologies. The proton conductivity of p5PhSA is $0.28 \mathrm{~S} / \mathrm{cm}$ at $40{ }^{\circ} \mathrm{C}$ and $95 \% \mathrm{RH}$. This conductivity is 4 times greater than Nafion 117 and exceeds that of many other hydrocarbon- 
based PEMs reported in the literature at similar conditions. From atomistic MD simulations, water diffusion rates increase with water content and are consistent with changes in the nanoscale morphology that reduce the influence of the hydrophilic / hydrophobic interface. This water diffusion is correlated with the measured proton conductivity providing a physical basis for the remarkable proton conductivity of p5PhSA. Thus, this work establishes that the high ion concentration and strong nanophase separation of p5PhS produce exceptional proton conductivity across a range of water contents. While further exploration of the thermal and mechanical properties is important, these results, along with the scalability and flexibility of ROMP synthesis, suggest p5PhSA and similar polymers as attractive candidates for fluorine-free proton conduction.

\section{ASSOCIATED CONTENT}

\section{Supporting Information}

Water Uptake, Conductivity Plots, MD Simulation Annealing, MD Snapshots, Scattering

Function Calculation from MD Simulations, Oxygen Coordination, Cross-sectional Area Analysis, MSD Plots

\section{AUTHOR INFORMATION}

\section{Corresponding Authors}

*Karen I Winey. E-mail: winey@ seas.upenn.edu

*Amalie L. Frischknecht. E-mail: alfrisc@ sandia.gov

*Mark J. Stevens. E-mail: msteve@ sandia.gov 


\section{Author Contributions}

The manuscript was written through contributions of all authors. All authors have given approval to the final version of the manuscript.

\section{Funding}

K.I.W. and B.A.P. acknowledge funding from the National Science Foundation (NSF) DMR 1904767, NSF PIRE 1545884, and the Vagelos Institute for Energy Science and Technology at the University of Pennsylvania for a graduate fellowship. B.A.P. and M.M. acknowledge funding from the Agence Nationale de la Recherche (ANR): ANR-15-PIRE-0001-01 and ANR-15-PIRE0001-04. J.G.K. acknowledges the National Science Foundation under Grant No. 1804871 and the Florida State University Energy and Materials Hiring Initiative for partial support of this research. This work was performed, in part, at the Center for Integrated Nanotechnologies, an Office of Science User Facility operated for the U.S. Department of Energy (DOE) Office of Science. Sandia National Laboratories is a multimission laboratory managed and operated by National Technology \& Engineering Solutions of Sandia, LLC, a wholly owned subsidiary of Honeywell International, Inc., for the U.S. DOE's National Nuclear Security Administration under contract DE-NA-0003525. The views expressed in the article do not necessarily represent the views of the U.S. DOE or the United States Government.

\section{Notes}

The authors declare no competing financial interests. 


\section{REFERENCES}

(1) Kusoglu, A.; Weber, A. Z. New Insights into Perfluorinated Sulfonic-Acid Ionomers. Chem. Rev. 2017, 117 (3), 987-1104.

(2) Allen, F. I.; Comolli, L. R.; Kusoglu, A.; Modestino, M. A.; Minor, A. M.; Weber, A. Z. Morphology of Hydrated As-Cast Nafion Revealed through Cryo Electron Tomography. ACS Macro Lett. 2015, 4 (1), 1-5.

(3) Byun, G. H.; Kim, J. A.; Kim, N. Y.; Cho, Y. S.; Park, C. R. Molecular Engineering of Hydrocarbon Membrane to Substitute Perfluorinated Sulfonic Acid Membrane for Proton Exchange Membrane Fuel Cell Operation. Mater. Today Energy 2020, 17, 100483.

(4) Park, C. H.; Lee, C. H.; Sohn, J. Y.; Park, H. B.; Guiver, M. D.; Lee, Y. M. Phase Separation and Water Channel Formation in Sulfonated Block Copolyimide. J. Phys. Chem. B 2010, 114 (37), 12036-12045.

(5) Peighambardoust, S. J.; Rowshanzamir, S.; Amjadi, M. Review of the Proton Exchange Membranes for Fuel Cell Applications; Elsevier Ltd, 2010; Vol. 35.

(6) Choi, P.; Jalani, N. H.; Datta, R. Thermodynamics and Proton Transport in Nafion. J. Electrochem. Soc. 2005, 152 (3), E123.

(7) Park, C. H.; Kim, T. H.; Nam, S. Y.; Hong, Y. T. Water Channel Morphology of NonPerfluorinated Hydrocarbon Proton Exchange Membrane under a Low Humidifying Condition. Int. J. Hydrogen Energy 2019, 44 (4), 2340-2348.

(8) Takamuku, S.; Jannasch, P. Properties and Degradation of Hydrocarbon Fuel Cell Membranes: A Comparative Study of Sulfonated Poly(Arylene Ether Sulfone)s with Different Positions of the Acid Groups. Polym. Chem. 2012, 3 (5), 1202-1214. 
(9) Wang, Z.; Ni, H.; Zhao, C.; Zhang, M.; Na, H. Physical and Electrochemical Behaviors of Directly Polymerized Sulfonated Poly(Arylene Ether Ketone Sulfone)s Proton Exchange Membranes with Different Backbone Structures. J. Appl. Polym. Sci. 2009, 112, 858-866.

(10) Trigg, E. B.; Gaines, T. W.; Maréchal, M.; Moed, D. E.; Rannou, P.; Wagener, K. B.; Stevens, M. J.; Winey, K. I. Self-Assembled Highly Ordered Acid Layers in Precisely Sulfonated Polyethylene Produce Efficient Proton Transport. Nat. Mater. 2018, 17 (8), 17.

(11) Shin, D. W.; Guiver, M. D.; Lee, Y. M. Hydrocarbon-Based Polymer Electrolyte Membranes: Importance of Morphology on Ion Transport and Membrane Stability. Chem. Rev. 2017, 117 (6), 4759-4805.

(12) Cui, S.; Liu, J.; Selvan, M. E.; Paddison, S. J.; Keffer, D. J.; Edwards, B. J. Comparison of the Hydration and Diffusion of Protons in Perfluorosulfonic Acid Membranes with Molecular Dynamics Simulations. J. Phys. Chem. B 2008, 112 (42), 13273-13284.

(13) Kendrick, A.; Neary, W. J.; Delgado, J. D.; Bohlmann, M.; Kennemur, J. G. Precision Polyelectrolytes with Phenylsulfonic Acid Branches at Every Five Carbons. Macromol. Rapid Commun. 2018, 39 (14), 1-7.

(14) Neary, W. J.; Kennemur, J. G. A Precision Ethylene-Styrene Copolymer with High Styrene Content from Ring-Opening Metathesis Polymerization of 4-Phenylcyclopentene. Macromol. Rapid Commun. 2016, 37 (12), 975-979.

(15) Kennemur, J. G.; Neary, W. J. Polystyrene Sulfonate Analogs and Methods. 10640587, 2020.

(16) Kieber, R. J.; Neary, W. J.; Kennemur, J. G. Viscoelastic, Mechanical, and Glasstomeric Properties of Precision Polyolefins Containing a Phenyl Branch at Every Five Carbons. 
Ind. Eng. Chem. Res. 2018, 57 (14), 4916-4922.

(17) Paren, B. A.; Thurston, B. A.; Neary, W. J.; Kendrick, A.; Kennemur, J. G.; Stevens, M.

J.; Frischknecht, A. L.; Winey, K. I. Percolated Ionic Aggregate Morphologies and

Decoupled Ion Transport in Precise Sulfonated Polymers Synthesized by Ring-Opening

Metathesis Polymerization. Macromolecules 2020, 53 (20), 8960-8973.

(18) Sorte, E. G.; Paren, B. A.; Rodriquez, C. G.; Fujimoto, C.; Poirier, C.; Lauren, J.; Lynd, N. A.; Winey, K. I.; Frischknecht, A. L.; Alam, T. M.; et al. Impact of Hydration and Sulfonation on the Morphology and Ionic Conductivity of Sulfonated Poly(Phenylene) Proton Exchange Membranes. Macromolecules 2019, 52 (3), 857-876.

(19) Lee, K. S.; Jeong, M. H.; Lee, J. P.; Kim, Y. J.; Lee, J. S. Synthesis and Characterization of Highly Fluorinated Cross-Linked Aromatic Polyethers for Polymer Electrolytes. Chem. Mater. 2010, 22 (19), 5500-5511.

(20) Zhang, X.; Hu, Z.; Luo, L.; Chen, S.; Liu, J.; Chen, S.; Wang, L. Graft-Crosslinked Copolymers Based on Poly(Arylene Ether Ketone)-Gc-Sulfonated Poly(Arylene Ether Sulfone) for PEMFC Applications. Macromol. Rapid Commun. 2011, 32 (14), 1108-1113.

(21) Olsson, J. S.; Pham, T. H.; Jannasch, P. Poly(Arylene Piperidinium) Hydroxide Ion Exchange Membranes: Synthesis, Alkaline Stability, and Conductivity. Adv. Funct. Mater. 2018, 28 (2), 1-10.

(22) Salas-De La Cruz, D.; Denis, J. G.; Griffith, M. D.; King, D. R.; Heiney, P. A.; Winey, K. I. Environmental Chamber for in Situ Dynamic Control of Temperature and Relative Humidity during X-Ray Scattering. Rev. Sci. Instrum. 2012, 83 (2).

(23) Abraham, M. J.; Murtola, T.; Schulz, R.; Páll, S.; Smith, J. C.; Hess, B.; Lindahl, E. GROMACS: High Performance Molecular Simulations through Multi-Level Parallelism 
from Laptops to Supercomputers. SoftwareX 2015, 1-2, 19-25.

(24) Pronk, S.; Páll, S.; Schulz, R.; Larsson, P.; Bjelkmar, P.; Apostolov, R.; Shirts, M. R.;

Smith, J. C.; Kasson, P. M.; van der Spoel, D.; et al. GROMACS 4.5: A High-Throughput and Highly Parallel Open Source Molecular Simulation Toolkit. Bioinformatics 2013, 29 (7), 845-854.

(25) Berendsen, H. J. C.; Spoel, D. van der; Drunen, R. van. GROMACS: A Message-Passing Parallel Molecular Dynamics Implementation. Comput. Phys. Commun. 1995, 91 (1-3), 43-56.

(26) Abraham, M. J.; Van Der Spoel, D.; Lindahl, E.; Hess, B.; team, the G. developement. GROMACS User Manual Version 2019.2; 2019.

(27) Jorgensen, W. L.; Maxwell, D. S.; Tirado-Rives, J. Development and Testing of the OPLS All-Atom Force Field on Conformational Energetics and Properties of Organic Liquids. $J$. Am. Chem. Soc. 1996, 118 (45), 11225-11236.

(28) Canongia Lopes, J. N.; Pádua, A. A. H.; Shimizu, K. Molecular Force Field for Ionic Liquids IV: Trialkylimidazolium and Alkoxycarbonyl-Imidazolium Cations;

Alkylsulfonate and Alkylsulfate Anions. J. Phys. Chem. B 2008, 112 (16), 5039-5046.

(29) Siu, S. W. I.; Pluhackova, K.; Böckmann, R. A. Optimization of the OPLS-AA Force Field for Long Hydrocarbons. J. Chem. Theory Comput. 2012, 8 (4), 1459-1470.

(30) Abascal, J. L. F.; Vega, C. A General Purpose Model for the Condensed Phases of Water: TIP4P/2005. J. Chem. Phys. 2005, 123 (23), 234505.

(31) Sagnella, D. E.; Voth, G. A. Structure and Dynamics of Hydronium in the Ion Channel Gramicidin A. Biophys. J. 1996, 70 (5), 2043-2051.

(32) Essmann, U.; Perera, L.; Berkowitz, M. L.; Darden, T.; Lee, H.; Pedersen, L. G. A 
Smooth Particle Mesh Ewald Method. J. Chem. Phys. 1995, 103 (19), 8577-8593.

(33) Leontyev, I. V.; Vener, M. V.; Rostov, I. V.; Basilevsky, M. V.; Newton, M. D.

Continuum Level Treatment of Electronic Polarization in the Framework of Molecular

Simulations of Solvation Effects. J. Chem. Phys. 2003, 119 (15), 8024-8037.

(34) Leontyev, I. V.; Stuchebrukhov, A. A. Electronic Continuum Model for Molecular Dynamics Simulations of Biological Molecules. J. Chem. Theory Comput. 2010, 6 (5), $1498-1508$.

Ryckaert, J.-P.; Ciccotti, G.; Berendsen, H. J. . Numerical Integration of the Cartesian Equations of Motion of a System with Constraints: Molecular Dynamics of n-Alkanes. 1977, 23 (3), 327-341.

(36) Hockney, R. .; Goel, S. .; Eastwood, J. . Quiet High-Resolution Computer Models of a Plasma. J. Comput. Phys. 1974, 14 (2), 148-158.

(37) Abbott, L. J.; Frischknecht, A. L. Nanoscale Structure and Morphology of Sulfonated Polyphenylenes via Atomistic Simulations. Macromolecules 2017, 50 (3), 1184-1192.

(38) Bussi, G.; Donadio, D.; Parrinello, M. Canonical Sampling through Velocity Rescaling. J. Chem. Phys. 2007, 126 (1).

(39) Berendsen, H. J. C.; Postma, J. P. M.; van Gunsteren, W. F.; DiNola, A.; Haak, J. R. Molecular Dynamics with Coupling to an External Bath. J. Chem. Phys. 1984, 81 (8), $3684-3690$.

(40) Gowers, R. J.; Linke, M.; Barnoud, J.; Reddy, T. J. E.; Melo, M. N.; Seyler, S. L.; Domański, J.; Dotson, D. L.; Buchoux, S.; Kenney, I. M. MDAnalysis: A Python Package for the Rapid Analysis of Molecular Dynamics Simulations. In Proceedings of the 15th Python in Science Conference; Benthall, S., Ed.; 2016; pp 98-105. 
(41) Lam, S. K.; Pitrou, A.; Seibert, S. Numba: A LLVM-Based Python JIT Compiler. In Proceedings of the second workshop on the LLVM compiler infrastructure in HPC;

LLVM '15; Association for Computing Machinery: New York, NY, USA, 2015.

(42) Kusoglu, A.; Savagatrup, S.; Clark, K. T.; Weber, A. Z. Role of Mechanical Factors in Controlling the Structure - Function Relationship of PFSA Ionomers. Macromolecules 2012, 45 (18), 7467-7476.

(43) Kim, Y. S.; Einsla, B.; Sankir, M.; Harrison, W.; Pivovar, B. S. Structure-PropertyPerformance Relationships of Sulfonated Poly(Arylene Ether Sulfone)s as a Polymer Electrolyte for Fuel Cell Applications. Polymer (Guildf). 2006, 47 (11), 4026-4035.

(44) Humphrey, W.; Dalke, A.; Schulten, K. Sartorius Products. J. Mol. Graph. 1996, 14 (October 1995), 33-38.

(45) Kreuer, K. D.; Portale, G. A Critical Revision of the Nano-Morphology of Proton Conducting Ionomers and Polyelectrolytes for Fuel Cell Applications. Adv. Funct. Mater. 2013, 23 (43), 5390-5397.

(46) Mantina, M.; Chamberlin, A. C.; Valero, R.; Cramer, C. J.; Truhlar, D. G. Consistent van Der Waals Radii for the Whole Main Group. J. Phys. Chem. A 2009, 113 (19), 58065812.

(47) Stone, J. An Efficient Library For Parallel Ray Tracing And Animation, University of Missouri--Rolla.

(48) Humphrey, W.; Dalke, A.; Schulten, K. VMD: Visual Molecular Dynamics. J. Mol. Graph. 1996, 14 (1), 33-38.

(49) Seitz, M. E.; Chan, C. D.; Opper, K. L.; Baughman, T. W.; Wagener, K. B.; Winey, K. I. Nanoscale Morphology in Precisely Sequenced Poly(Ethylene- Co -Acrylic Acid) Zinc 
Ionomers. J. Am. Chem. Soc. 2010, 132 (23), 8165-8174.

(50) Buitrago, C. F.; Bolintineanu, D. S.; Seitz, M. E.; Opper, K. L.; Wagener, K. B.; Stevens, M. J.; Frischknecht, A. L.; Winey, K. I. Direct Comparisons of X-Ray Scattering and Atomistic Molecular Dynamics Simulations for Precise Acid Copolymers and Ionomers. Macromolecules 2015, 48 (4), 1210-1220.

(51) Frischknecht, A. L.; Winey, K. I. The Evolution of Acidic and Ionic Aggregates in Ionomers during Microsecond Simulations. J. Chem. Phys. 2019, 150 (6), 064901.

(52) Middleton, L. R.; Tarver, J. D.; Cordaro, J.; Tyagi, M.; Soles, C. L.; Frischknecht, A. L.; Winey, K. I. Heterogeneous Chain Dynamics and Aggregate Lifetimes in Precise AcidContaining Polyethylenes: Experiments and Simulations. Macromolecules 2016, 49 (23), 9176-9185.

(53) Abbott, L. J.; Frischknecht, A. L. Nanoscale Structure and Morphology of Sulfonated Polyphenylenes via Atomistic Simulations. Macromolecules 2017, 50 (3), 1184-1192.

(54) Santos, L. Dos; Maréchal, M.; Guillermo, A.; Lyonnard, S.; Moldovan, S.; Ersen, O.; Sel, O.; Perrot, H.; Laberty-Robert, C. Proton Transport in Electrospun Hybrid OrganicInorganic Membranes: An Illuminating Paradox. Adv. Funct. Mater. 2016, 26 (4), 594604.

(55) Kreuer, K.-D.; Dippel, T.; Meyer, W.; Maier, J. Nafion® Membranes: Molecular Diffusion, Proton Conductivity and Proton Conduction Mechanism. In MRS Online Proc. Libr.; 1993; Vol. 293, pp 273-282.

(56) Holz, M.; Heil, S. R.; Sacco, A. Temperature-Dependent Self-Diffusion Coefficients of Water and Six Selected Molecular Liquids for Calibration in Accurate 1H NMR PFG Measurements. Phys. Chem. Chem. Phys. 2000, 2 (20), 4740-4742. 
(57) Yoshida, K.; Matubayasi, N.; Nakahara, M. Self-Diffusion Coefficients for Water and Organic Solvents at High Temperatures along the Coexistence Curve. J. Chem. Phys. 2008, $129(21)$.

(58) Kreuer, K. D. On the Development of Proton Conducting Materials for Technological Applications. Solid State Ionics 1997, 97 (1-4), 1-15. 
Table of contents image:

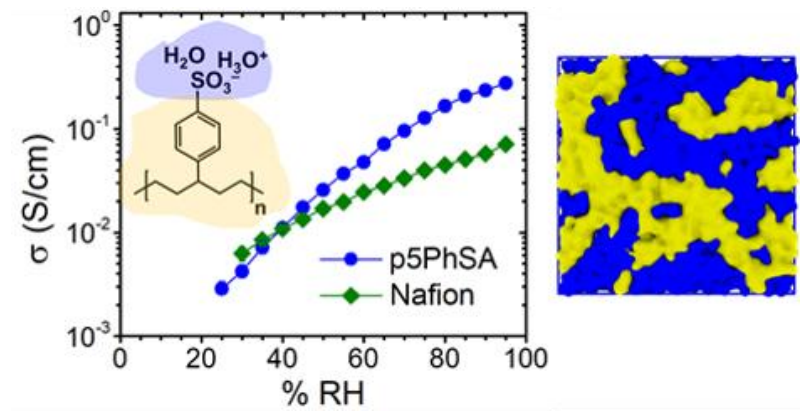

